\title{
Inhibition of thyroid hormone signaling protects retinal pigment epithelium and photoreceptors from cell death in a mouse model of age-related macular degeneration
}

\author{
Hongwei Ma', Fan Yang ${ }^{1}$ and Xi-Qin Ding ${ }^{1}$
}

\begin{abstract}
Age-related macular degeneration (AMD) is the leading cause of blindness in the elderly. Dry AMD is characterized by a progressive macular degeneration of the retinal pigment epithelium (RPE) and photoreceptors, and the RPE oxidative damage/dystrophy is at the core of the disease. Recent population/patients-based studies have shown an association of high free serum thyroid hormone $(\mathrm{TH})$ levels with increased risk of AMD. This work investigated the effects of TH signaling inhibition on RPE and photoreceptor damage/cell death in an oxidative stress-induced mouse model of AMD. TH signaling inhibition was achieved by anti-thyroid drug treatment and oxidative stress was induced by sodium iodate $\left(\mathrm{NalO}_{3}\right)$ administration. Mice treated with $\mathrm{NalO}_{3}$ showed severe RPE and photoreceptor cell death/ necroptosis, destruction, oxidative damage, retinal stress, and reduced retinal function. Treatment with anti-thyroid drug protected RPE and photoreceptors from damage/cell death induced by $\mathrm{NalO}_{3}$, reduced oxidative damage of RPE and photoreceptors, and preserved retinal function. Gene expression analysis showed that the $\mathrm{NalO}_{3}$-induced RPE/ photoreceptor damage/cell death involves multiple mechanisms, including cellular oxidative stress responses, activation of necroptosis/apoptosis signaling, and inflammatory responses. Treatment with anti-thyroid drug abolished these cellular stress/death responses. The findings of this study demonstrate a role of TH signaling in RPE and photoreceptor cell death after oxidative stress challenge, and support a role of TH signaling in the pathogenesis of AMD.
\end{abstract}

\section{Introduction}

Age-related macular degeneration (AMD) is the leading cause of blindness in elderly, exhibiting complex interplay of genetic and environmental factors ${ }^{1,2}$. There are two types of AMD, the dry and wet forms. Dry AMD, also known as geographic atrophy, is a form of slowly progressing geographic atrophy of the macula, and comprises a majority of AMD cases ( $90 \%)$, whereas wet AMD rapidly progresses to blindness and involves the abnormal formation of blood vessels in the macula. Dry AMD is

Correspondence: Xi-Qin Ding (xi-qin-ding@ouhsc.edu)

'Department of Cell Biology, University of Oklahoma Health Sciences Center, Oklahoma City, OK, USA

Edited by N. Bazan characterized by a progressive macular degeneration of the retinal pigment epithelial (RPE) cells and photoreceptors, lipofuscin (A2E) accumulation, and drusen formation. It is generally recognized that multiple factors, including aging, oxidative stress, chronic inflammation, and genetic defects, are involved in the RPE and photoreceptor dystrophies/AMD lesions. However, oxidative stress/damage to the RPE has been recognized as the core pathogenic lesion of the disease $\mathrm{e}^{2-4}$.

Thyroid hormone $(\mathrm{TH})$ signaling regulates numerous physiological functions, including cell growth, differentiation, and metabolic homeostasis. In the eye, $\mathrm{TH}$ signaling regulates cone opsin expression ${ }^{5,6}$ and cone photoreceptor viability ${ }^{7-10}$. Recently, $\mathrm{TH}$ signaling has 
been implicated in the pathogenesis of AMD. The prospective population-based studies showed that higher free serum $\mathrm{TH}$ values were associated with increased risk of $\mathrm{AMD}^{11-13}$. The patient population-based study also showed a high association between thyroidopathy and $\mathrm{AMD}^{14,15}$. These findings suggest an association of $\mathrm{TH}$ signaling with AMD. Indeed TH signaling has been linked to other types of neurodegenerative conditions, including Alzheimer's disease ${ }^{16,17}$. The present work investigated the effects of TH signaling inhibition on RPE and photoreceptor damage/cell death in a mouse model of AMD induced by sodium iodate $\left(\mathrm{NaIO}_{3}\right)$. We found that treatment with anti-thyroid drug protected RPE and photoreceptors from oxidative damage and cell death/ necroptosis induced by $\mathrm{NaIO}_{3}$ and preserved retinal function. Moreover, treatment with anti-thyroid drug abolished $\mathrm{NaIO}_{3}$-induced upregulation of the genes involved in cellular stress responses, inflammatory responses, and cell death signaling. The findings of this study demonstrate a role of $\mathrm{TH}$ signaling in RPE and photoreceptor cell death induced by oxidative stress challenge and support a role of $\mathrm{TH}$ signaling in the development and progression of AMD.

\section{Results}

Treatment with anti-thyroid drug protected RPE and photoreceptors from damage and cell death induced by $\mathrm{NaIO}_{3}$

A single treatment of $\mathrm{NaIO}_{3}$ induces RPE and photoreceptor oxidative damage/cell death, mimicking the feature and progression of $\mathrm{AMD}^{18-20}$. This model has been commonly used to study RPE and photoreceptor oxidative damage in AMD. To determine the role of $\mathrm{TH}$ signaling in oxidative stress-induced damage and cell death, we examined the effects of anti-thyroid treatment in mice that have been treated with $\mathrm{NaIO}_{3}$. C57BL/6J mice received anti-thyroid treatment via drinking water ( $1 \%$ sodium perchlorate monohydrate and $0.05 \%$ methomazole), beginning at postnatal day 20 (P20), received a single injection of $\mathrm{NaIO}_{3}(30 \mathrm{mg} / \mathrm{kg}$, i.p.) at P30, and were then analyzed for RPE and photoreceptor damage/cell death at 3 days post- $\mathrm{NaIO}_{3}$ injection. ELISA analysis showed that the serum triiodothyronine (T3) level in antithyroid-treated mice were reduced by about $70 \%$, compared with untreated controls (Supplementary Fig. 1). RPE morphology and cell loss were evaluated by phalloidin staining for F-actin and DAPI staining for nucleus on RPE whole mounts. As reported, treatment with $\mathrm{NaIO}_{3}$ induced severe damage of RPE, particularly in the central and middle regions (Fig. 1a). The RPE cells in $\mathrm{NaIO}_{3}$-treated mice were either completely lost in the severely damaged areas or were enlarged or irregularly shaped in the damaged and undamaged junction areas. Treatment with anti-thyroid drug profoundly preserved
RPE cells from death. Evaluations of the low magnification images showed that the $\mathrm{NaIO}_{3}$ treatment caused damage in about $46 \%$ of the entire RPE area, and treatment with anti-thyroid drug nearly completely protected RPE cells (Fig. 1a). Evaluations of RPE cell numbers and nuclear numbers were performed on the high magnification images. The RPE cell numbers in the central and middle regions in $\mathrm{NaIO}_{3}$-treated mice were reduced by about $84 \%$ and $60 \%$, respectively, compared with untreated controls, and anti-thyroid treatment completely prevented these reductions (Fig. 1b). Similar results were obtained from evaluations of the RPE nuclear numbers (Fig. 1b). The RPE layer integrity was also evaluated on eye cross sections with $\mathrm{H} \& \mathrm{E}$ staining. In $\mathrm{NaIO}_{3}$-treated mice, RPE layer in the middle and central regions exhibited thinner, gap and swelling, and possible macrophage infusion. Treatment with anti-thyroid drug greatly preserved RPE layer integrity, showing nearly normal RPE layer morphology (Supplementary Fig. 2A). Quantitative analysis revealed that the RPE nuclear numbers in $\mathrm{NaIO}_{3}-$ treated mice was reduced by about $60 \%$, compared with untreated controls, and the nuclear numbers in mice received anti-thyroid treatment was only reduced by about 10\% (Supplementary Fig. 2B). Treatment with antithyroid drug alone did not induce any detectable changes in RPE morphology and cell loss (Supplementary Fig. 3).

In a separate experiment, we examined the effects of anti-thyroid drug treatment in aged mice. At 17 months of age, mice received anti-thyroid treatment, followed by a single injection of $\mathrm{NaIO}_{3}$ on the 10th day from the start of the anti-thyroid treatment, as described above. Mice were then analyzed for RPE morphology at 2 days post- $\mathrm{NaIO}_{3}$ injection. Evaluation of the low magnification images of phalloidin staining showed that the $\mathrm{NaIO}_{3}$ treatment caused damage in about $87 \%$ of the RPE area, and treatment with anti-thyroid drug reduced the damage to about $70 \%$ of the RPE area (Fig. 1c). Figure 1d shows high magnification images of phalloidin labeling and DAPI staining at different regions of RPE. Similar to young mice, treatment with anti-thyroid drug alone did not induce any detectable changes in RPE morphology and cell loss in aged mice (Supplementary Fig. 4).

Retinal morphology/photoreceptor numbers were evaluated on retinal cross sections and retinal whole mounts. The retinal section examinations showed severe damage of photoreceptor layer in mice after $\mathrm{NaIO}_{3}$ challenge. These mice displayed disorganized outer nuclear layer (ONL) and outer segment (OS) areas, reduced numbers/ thickness of the ONL, and shortened OS (Fig. 2a). Treatment with anti-thyroid drug greatly preserved retinal morphology and prevented photoreceptor cell loss induced by $\mathrm{NaIO}_{3}$. The ONL thickness in the central retina was reduced by about $27 \%$ in mice after $\mathrm{NaIO}_{3}$ injection, and treatment with anti-thyroid drug nearly 


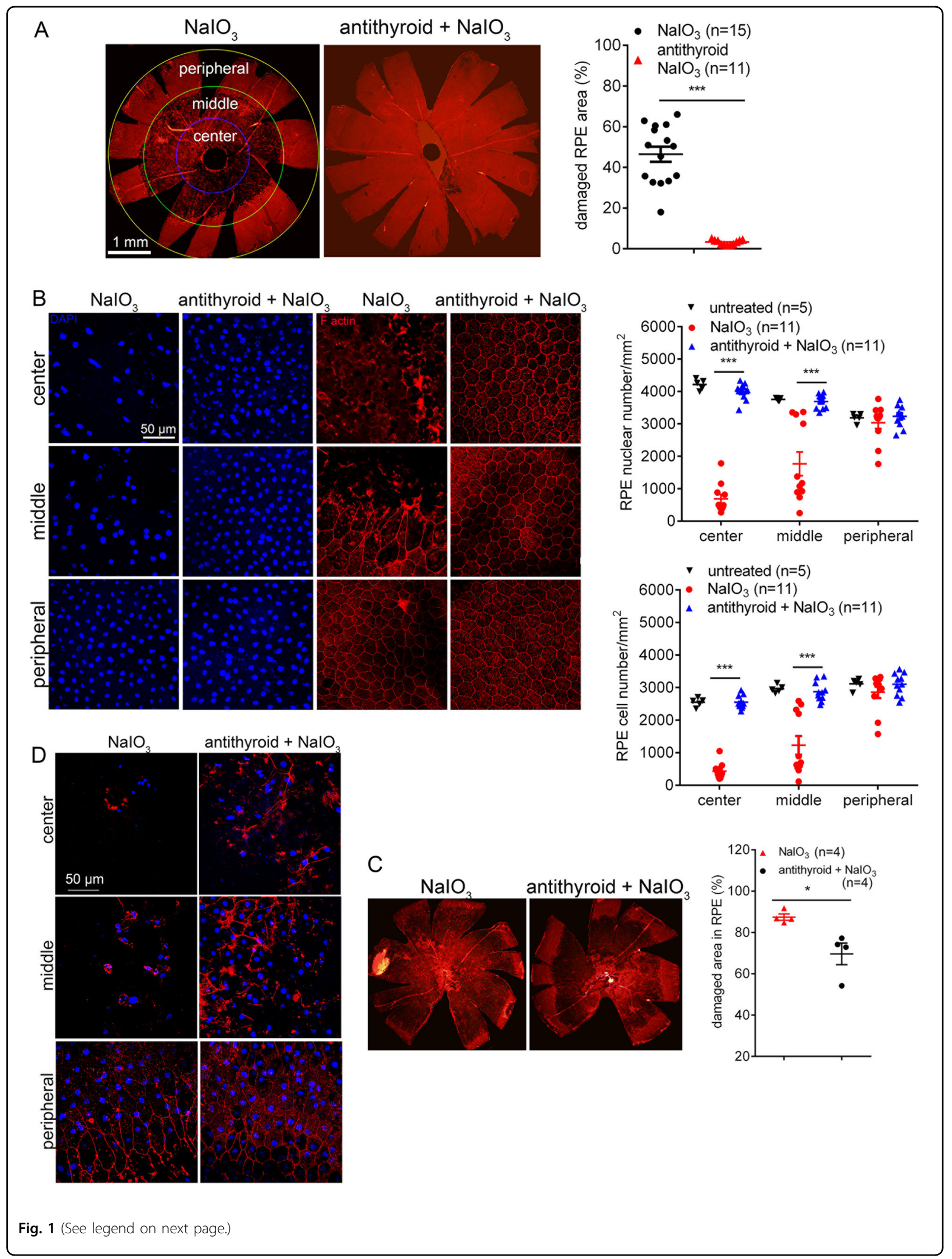


(see figure on previous page)

Fig. 1 Treatment with anti-thyroid drug protected RPE from damage and cell loss induced by $\mathrm{NalO}_{3}$. RPE morphology and cell loss were evaluated by phalloidin staining for F-actin and DAPI staining for nucleus on RPE whole mounts at 2-3 days post-NalO ${ }_{3}$ injection. $\mathbf{a}$, b Shown are RPE morphology evaluations in P30 mice. a Shown are representative low magnification images of phalloidin staining and corresponding quantitative analysis of the damaged area in the RPE. $\mathbf{b}$ Shown are representative high magnification images of phalloidin staining and DAPI labeling taken at different regions of the RPE, and corresponding quantitative analysis of RPE cell numbers and RPE nuclear numbers. Data represented the mean \pm SEM for 5-15 mice per group $\left({ }^{* *} p<0.001\right)$. c, d Shown are RPE morphology evaluations in 17-month-old mice. c Shown are representative low magnification images of phalloidin staining and corresponding quantitative analysis of the damaged area in the RPE. $\mathbf{d}$ Shown are representative high magnification images of phalloidin staining and DAPI labeling taken at different regions of the RPE. Data represented the mean \pm SEM for four mice per group $\left({ }^{*} p<0.05\right)$.

completely prevented the loss of photoreceptors (Fig. 2a). Peanut agglutinin (PNA) labeling on retinal whole mounts showed that $\mathrm{NaIO}_{3}$ injection reduced cone number by about $30 \%$, compared with untreated controls, and treatment with anti-thyroid drug greatly preserved cones (Fig. 2b).

The effects of anti-thyroid drug treatment were further evaluated by examining the molecular hallmarks of cell death. Propidium iodide (PI) staining has previously indicated $\mathrm{NaIO}_{3}$-induced RPE cell necroptosis, with abundant PI staining at 2 days post- $\mathrm{NaIO}_{3}$ injection ${ }^{18}$. At 2 days post-injection, we performed a retro-orbital PI injection for PI staining, and observed that $\mathrm{NaIO}_{3}$ treatment induced remarkable PI staining, while treatment with anti-thyroid drug nearly completely abolished the staining (Fig. 3a). Treatment with anti-thyroid drug alone did not induce any detectable PI staining (data not shown). Terminal deoxynucleotidyltransferase dUTP nick-end labeling (TUNEL)-positive RPE cells and TUNEL-positive photoreceptor cells have been detected at 1 to 3 days post- $\mathrm{NaIO}_{3}$ injection ${ }^{18}$. We performed TUNEL to evaluate the effects of anti-thyroid treatment. TUNEL-positive cells were detected on the RPE whole mounts at 1 day post- $\mathrm{NaIO}_{3}$ injection; anti-thyroid treatment abolished the TUNEL detection (Fig. 3b). Retinal section analysis revealed a large increase in the numbers of TUNEL-positive photoreceptor cells at 3 days post- $\mathrm{NaIO}_{3}$ injection; treatment with anti-thyroid drug eliminated the TUNEL labeling (Fig. 3c).

\section{Treatment with anti-thyroid drug protected RPE and} photoreceptors from oxidative damage induced by $\mathrm{NaIO}_{3}$

We next examined the effects of anti-thyroid treatment on RPE and photoreceptor oxidative damage. Mice received anti-thyroid treatment and $\mathrm{NaIO}_{3}$ challenge, as described above, and were analyzed for RPE and photoreceptor oxidative damage at 3 days post- $\mathrm{NaIO}_{3}$ injection. RPE oxidative damage were assessed by immunofluorescence labeling of the DNA double strand break/ damage markers $\mathrm{p}-\gamma \mathrm{H} 2 \mathrm{AX}$ and $8-\mathrm{OHdG}$ on the RPE whole mounts ${ }^{21,22}$. Mice that have been treated with $\mathrm{NaIO}_{3}$ showed significantly increased labeling of p- $\gamma \mathrm{H} 2 \mathrm{AX}$, compared with untreated controls (Fig. 4a). The labeling signal was concentrated in the central and middle regions, correlating to the RPE damage pattern in which more cell death was found in these regions. Treatment with anti-thyroid drug greatly reduced $\mathrm{NaIO}_{3}$-induced elevation of $\mathrm{p}-\gamma \mathrm{H} 2 \mathrm{AX}$ (Fig. 4a). Similar findings were obtained with $\mathrm{p}-\gamma \mathrm{H} 2 \mathrm{AX}$ labeling on the retinal sections. Mice that have been treated with $\mathrm{NaIO}_{3}$ showed greatly increased labeling of $\mathrm{p}-\gamma \mathrm{H} 2 \mathrm{AX}$ in the ONL layer, compared with untreated controls, and treatment with antithyroid drug completely abolished $\mathrm{NaIO}_{3}$-induced elevation of p- $\gamma \mathrm{H} 2 \mathrm{AX}$ (Fig. 4b). The effects of antithyroid drug on $\mathrm{NaIO}_{3}$-induced oxidative damage was also demonstrated by $8-\mathrm{OHdG}$ labeling (Fig. 4b).

\section{Treatment with anti-thyroid drug suppressed Müller glia activation induced by $\mathrm{NaIO}_{3}$}

Müller glia are known to activate in response to retinal stress by profound upregulation of glial fibrillary acidic protein (GFAP) in intermediate filaments. In this study, we examined the effects of anti-thyroid treatment on Müller glia activation. Mice received anti-thyroid treatment and $\mathrm{NaIO}_{3}$ challenge, as described above, and were analyzed for Müller glia activation at 3 days post- $\mathrm{NaIO}_{3}$ injection. Retinal cross sections were analyzed for expression of GFAP by immunofluorescence labeling. Quantitative analysis of the immunofluorescence intensity showed that the $\mathrm{NaIO}_{3}$ treatment increased expression of GFAP by about $67 \%$, compared with untreated controls, and treatment with anti-thyroid drug completely abolished the $\mathrm{NaIO}_{3}$-induced GFAP expression (Fig. 5).

\section{Treatment with anti-thyroid drug preserved retinal function in mice treated with $\mathrm{NaIO}_{3}$}

We also examined the effects of anti-thyroid treatment on retinal function. Mice received anti-thyroid treatment and $\mathrm{NaIO}_{3}$ challenge, as described above, and were analyzed for retinal function by electroretinogram (ERG) recordings at 3 days post- $\mathrm{NaIO}_{3}$ injection. $\mathrm{NaIO}_{3}$ treatment reduced scotopic a- and b-wave amplitudes by about 55 and 44\%, respectively, compared with untreated controls, and treatment with anti-thyroid drug significantly 

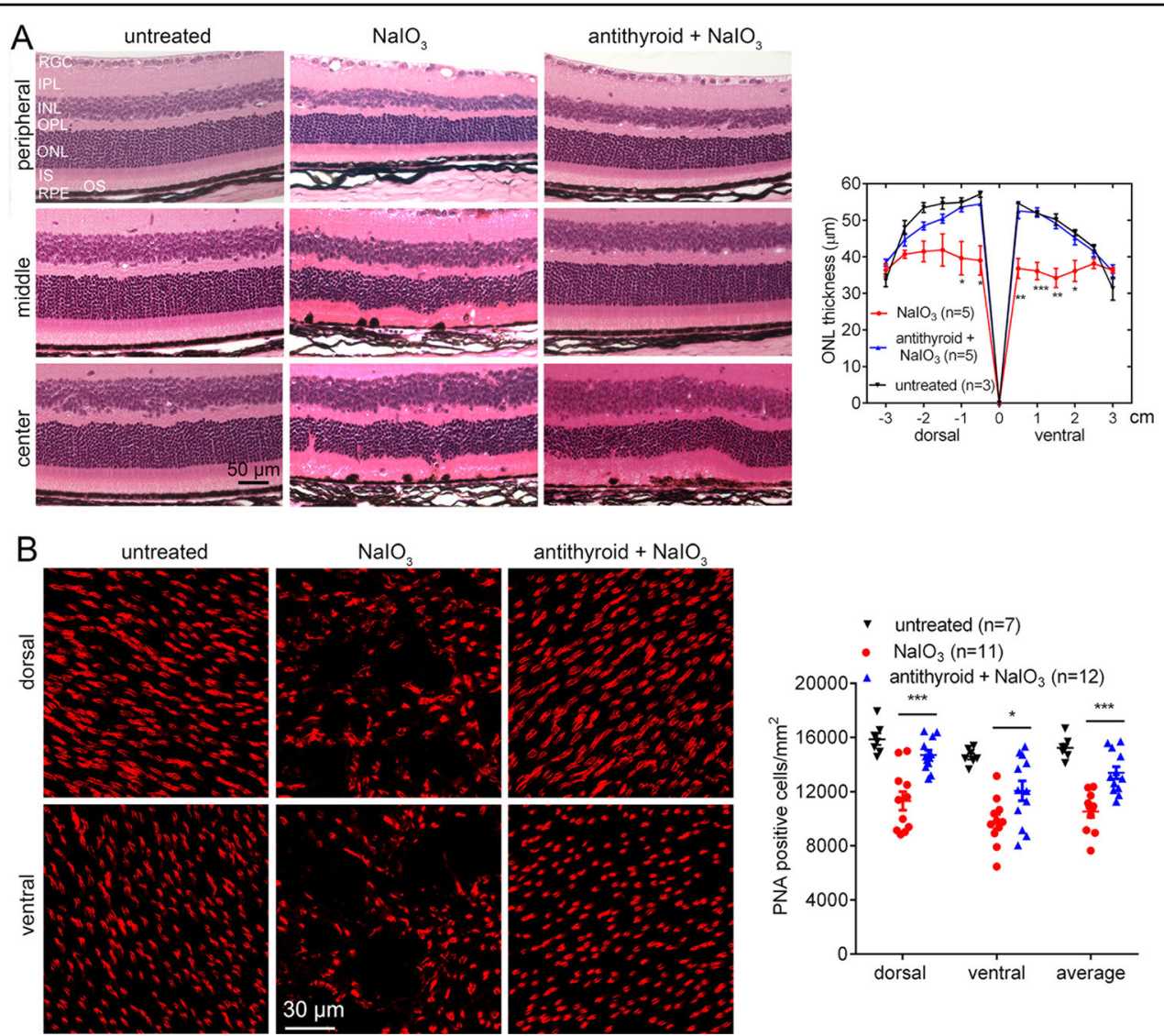

Fig. 2 Treatment with anti-thyroid drug protected photoreceptors from cell loss/degeneration induced by $\mathrm{NaIO}_{3}$. Retinal morphology, photoreceptor layer integrity, and loss of photoreceptors were evaluated by light microscope and morphometric analysis at 3 days post-NalO injection, and cone density was evaluated by PNA labeling on retinal whole mounts. a Shown are representative light microscopic images of H\&E stained retinal sections, and corresponding quantitative analysis of ONL thickness in the dorsal and ventral regions. Data represented the mean \pm SEM for 3-5 mice each group. $\mathbf{b}$ Shown are representative confocal images of PNA labeling on retinal whole mounts, and corresponding quantitative analysis. RPE, retinal pigment epithelial; OS, outer segment; IS, inner segment; ONL, outer nuclear layer; OPL, outer plexiform layer; INL, inner nuclear layer; IPL, inner plexiform layer; RGC, retinal ganglion cell. Data represented the mean \pm SEM for $7-12$ mice per group $\left({ }^{*} p<0.05 ;{ }^{* *} p<0.01 ;{ }^{* * *} p<\right.$ $0.001)$.

preserved scotopic b-wave but not a-wave responses (Fig. 6). Similarly, $\mathrm{NaIO}_{3}$ treatment reduced photopic b-wave amplitudes by about 39\%, compared with untreated controls, and treatment with anti-thyroid drug completely preserved photopic b-wave responses (Fig. 6).

\section{Treatment with anti-thyroid drug reversed the $\mathrm{NaIO}_{3}-$ induced gene expression upregulation in the RPE and retina}

To explore the mechanisms underlying $\mathrm{TH}$ signaling suppression-induced protection, we examined expression of the genes involved in oxidative stress responses, including Gpx4, Nox4, and Ncf1, apoptosis/necroptosis pathways, including Casp3, Casp7, Casp8, Tnfrsf1 1 , Ripk1, Ripk3, Mik1, and inflammatory responses, including Nirp3, Il-1 $\alpha / \beta, I l-6$, and Il22. Mice received antithyroid treatment and $\mathrm{NaIO}_{3}$ challenge, as described above, and were analyzed for gene expression in the RPE and retina by qRT-PCR at 1 day post- $\mathrm{NaIO}_{3}$ injection. $\mathrm{NaIO}_{3}$ treatment significantly induced expression of these genes in the RPE (Fig. 7) and retina (Fig. 8), and treatment with anti-thyroid drug nearly completely abolished the upregulation of the gene expression induced by $\mathrm{NaIO}_{3}$ (Figs. 7-8). Treatment with anti-thyroid drug alone did not induce significant expression alteration of these genes (Figs. 7-8). In a comparison between RPE and retinas, we found that the apoptotic genes were similarly upregulated in the RPE and retina, there were more oxidative stress response genes upregulated in the RPE than that in the retina, and there was more significant elevation of the necroptosis genes and inflammatory genes in the retina than that in the RPE.

\section{Discussion}

$\mathrm{NaIO}_{3}$ induces RPE dystrophies/photoreceptor degeneration, primarily by inducing oxidative stress, mimicking 


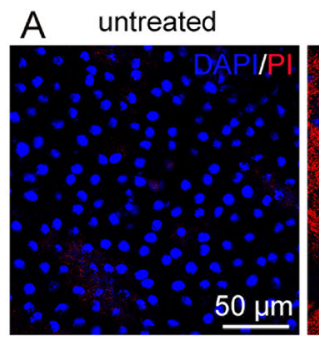

B untreated
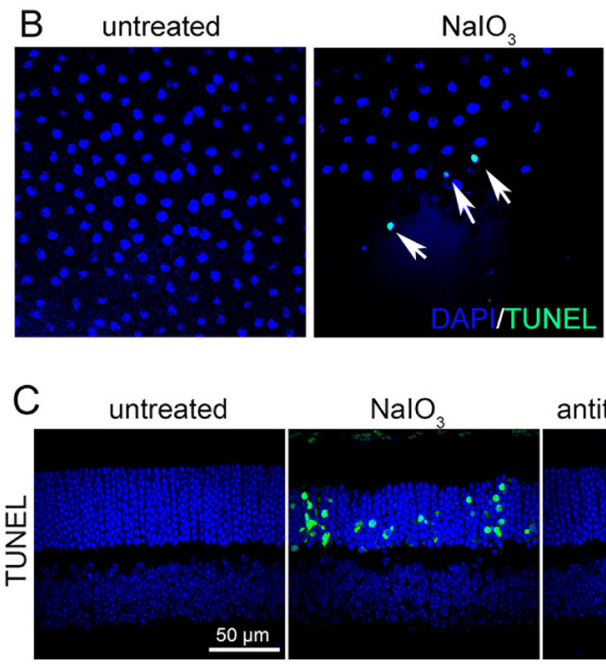

$\mathrm{NaIO}$

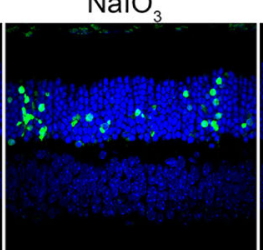

antithyoid + $\mathrm{NaIO}$

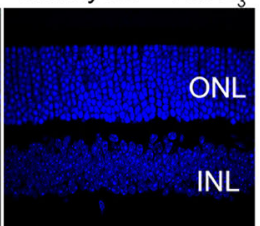

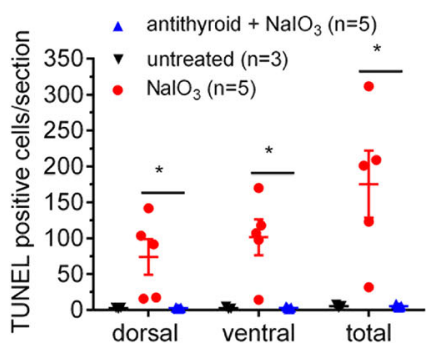

Fig. 3 Treatment with anti-thyroid drug protected RPE cells and photoreceptor cells from necroptosis induced by $\mathrm{NaIO}_{3} . \mathbf{a}, \mathbf{b}$ RPE cell necroptosis was evaluated by PI staining and TUNEL on the RPE whole mounts. Shown are representative images of PI staining at the middle region of the RPE at 2 days post- $\mathrm{NaIO}_{3}$ injection and correlating quantitative analysis (a), and representative images of TUNEL at the middle region of the RPE at 1 day post- $\mathrm{NaIO}_{3}$ injection (b). c Photoreceptor cell apoptosis was evaluated by TUNEL on the retinal sections at 3 days post-NalO ${ }_{3}$ injection. Shown are representative images of TUNEL and correlating quantitative analysis. ONL, outer nuclear layer; INL, inner nuclear layer. Data represented the mean \pm SEM for $3-5$ mice per group $\left({ }^{*} p<0.05,{ }^{* *} p<0.01\right)$.

the feature and progression of $\mathrm{AMD}^{23}$. A single administration of $\mathrm{NaIO}_{3}$ (by i.v., i.p. or intraocular injection) selectively induces RPE oxidative damage in experimental animals in a concentration-dependent manner, with more severe damage in the central and middle regions of the $\mathrm{RPE}^{24,25}$. Photoreceptors degenerate as results of RPE cell loss and the drug's direct action. $\mathrm{NaIO}_{3}$ challenge has been used in various animal models, including mouse $\mathrm{e}^{26-28}$, rat $^{29,30}$, rabbit $^{30,31}$, sheep ${ }^{32}$ cat $^{33}$, and swine ${ }^{30,34,35}$, to study $\mathrm{RPE} /$ photoreceptor oxidative damage in AMD, and evaluate the novel therapeutic interventions. In the present study, we used this model to investigate the effects of $\mathrm{TH}$ signaling inhibition. As expected, a single injection of $\mathrm{NaIO}_{3}$ caused severe damage of RPE and photoreceptors, activated multiple cellular stress/death pathways, and impaired retinal function. Treatment with anti-thyroid drug nearly completely preserved RPE and photoreceptors from damage/cell death, reversed gene expression alterations, and partially preserved retinal function. These findings demonstrate a role of TH signaling in RPE and photoreceptor cell damage/ death induced by $\mathrm{NaIO}_{3}$ /oxidative stress. The observed effects from anti-thyroid treatment likely resulted from the reduced $\mathrm{TH}$ levels in the circulation (anti-thyroid drug treatment reduced the serum T3 level by about $67 \%$; see Supplemental Fig. 1) and the subsequently reduced TH signaling in the target tissues/cells. Investigation using mice with deficiency of $\mathrm{TH}$ receptors will provide further insight.

We also examined the effects of anti-thyroid drug treatment in aged 17-month-old mice. We found that the aged mice displayed much more severe RPE damage/loss after $\mathrm{NaIO}_{3}$ challenge (87\% damage area, Fig. 1c) than did the young mice ( $46 \%$ damage area, Fig. 1a). This finding suggests that the aged mice were more sensitive to $\mathrm{NaIO}_{3} /$ oxidative challenge. In addition, the protective effects from anti-thyroid treatment were less significant in the aged mice than in the young mice. Anti-thyroid treatment nearly completely protected RPE from damage/cell loss in the young mice (see Fig. 1a), but only partly, though significantly, protected RPE cells in the aged mice. The difference in the protection efficiency might be associated with much more severe damage and/or less responsiveness to the anti-thyroid treatment in the aged mice. 

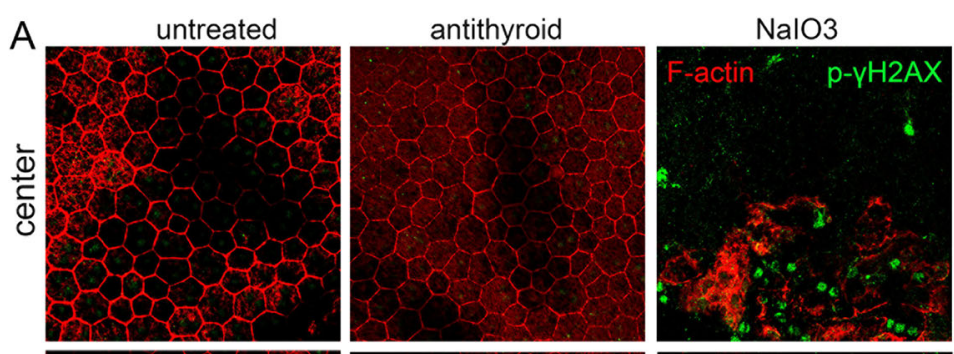

antithyoid $+\mathrm{NalO} 3$
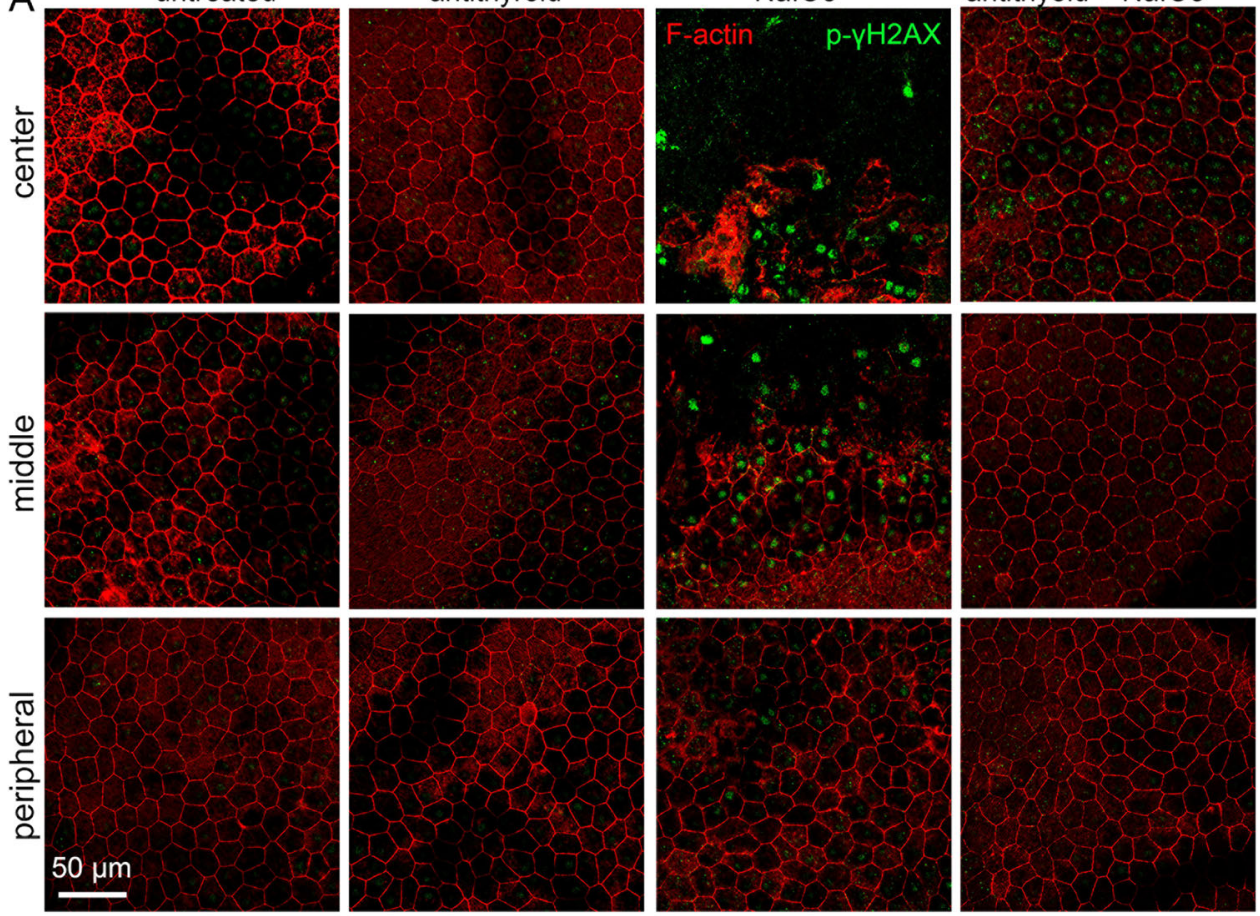

B

untreated

$\mathrm{NaIO}_{3}$

antithyoid $+\mathrm{NalO}_{3}$
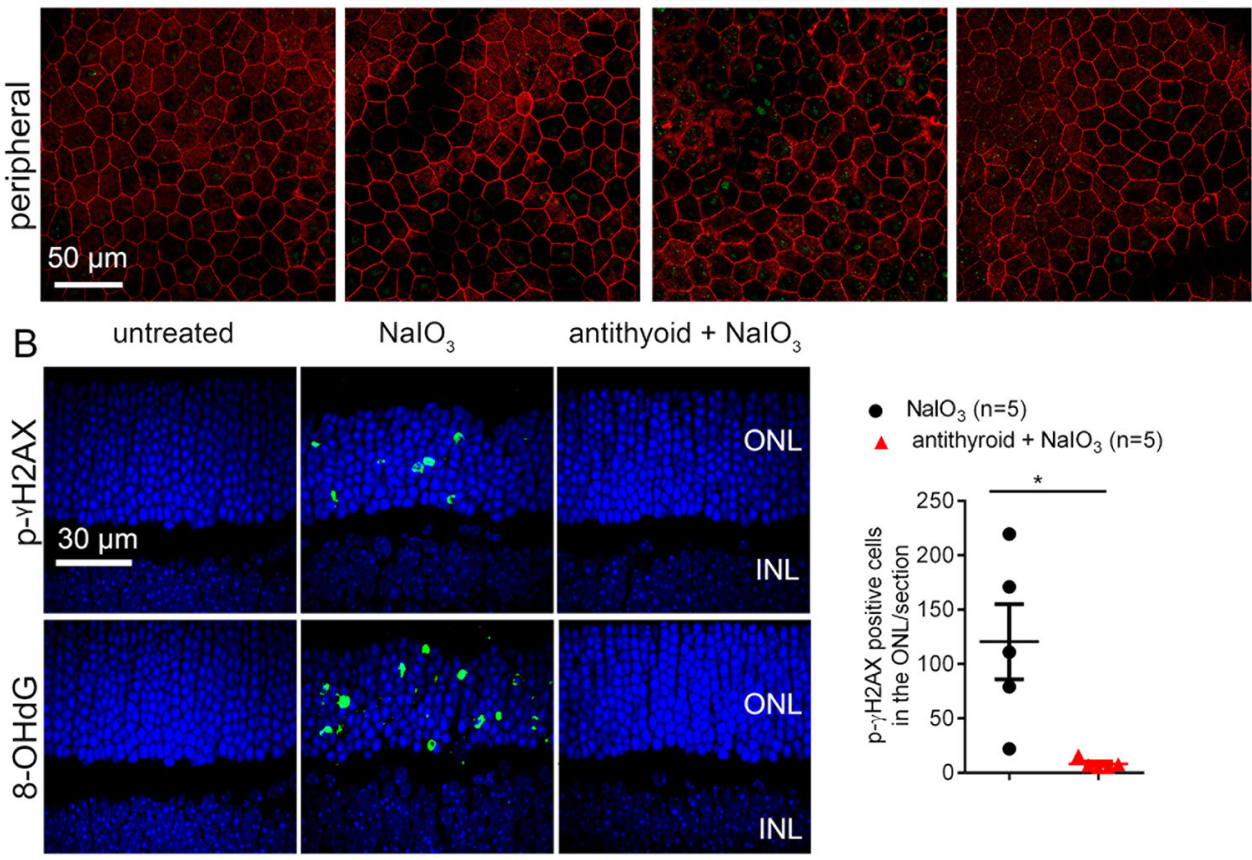

Fig. 4 Treatment with anti-thyroid drug protected RPE and photoreceptors from oxidative damage induced by $\mathrm{NalO}_{3}$. RPE and retinal oxidative damage were evaluated by immunofluorescence labeling of $\mathrm{p}-\mathrm{\gamma H} 2 \mathrm{AX}$ and $8-\mathrm{OHdG}$ on the RPE whole mounts and retinal sections at 3 days post- $\mathrm{NalO}_{3}$ injection. a Shown are representative images of $\mathrm{p}-\mathrm{\gamma H} 2 \mathrm{AX}$ immunofluorescence labeling on the RPE whole mounts. $\mathbf{b}$ Shown are representative images of $\mathrm{p}-\mathrm{\gamma} \mathrm{H} 2 \mathrm{AX}$ and $8-\mathrm{OHdG}$ immunofluorescence labeling on the retinal sections, and corresponding quantitative analysis for $\mathrm{p}-\mathrm{\gamma H} 2 \mathrm{AX}$ labeling. ONL, outer nuclear layer; $\mathrm{INL}$, inner nuclear layer. Data represented the mean \pm SEM for 5 mice per group $\left(^{*} p<0.05\right)$.

Because photoreceptor damage/cell death after $\mathrm{NaIO}_{3}$ administration is a consequence of the loss/dysfunction of RPE and the direct harmful action of $\mathrm{NaIO}_{3}{ }^{36,37}$, the observed photoreceptor protection was likely achieved via the indirect protection from reduced RPE damage and the direct protection. TH regulation of cone survival has been well documented previously. Excessive $\mathrm{TH}$ signaling causes cone degeneration, whereas suppression of $\mathrm{TH}$ signaling protects cones in mouse models of inherited retinal degeneration ${ }^{7-10,38}$. Compared with the understanding of $\mathrm{TH}$ regulation of cone survival, we know little about $\mathrm{TH}$ regulation of rod survival. This work for the first time shows rod protection by $\mathrm{TH}$ signaling suppression in a mouse model of retinal degeneration, demonstrating a regulation of $\mathrm{TH}$ signaling in rod viability, which merits further investigation. The present study also demonstrates a protection of retinal function by $\mathrm{TH}$ signaling suppression. Anti-thyroid treatment completely reversed the reduction of ERG b-wave amplitudes induced by $\mathrm{NaIO}_{3}$. This functional rescue was likely resulted from the protection of retinal morphology/reduced 


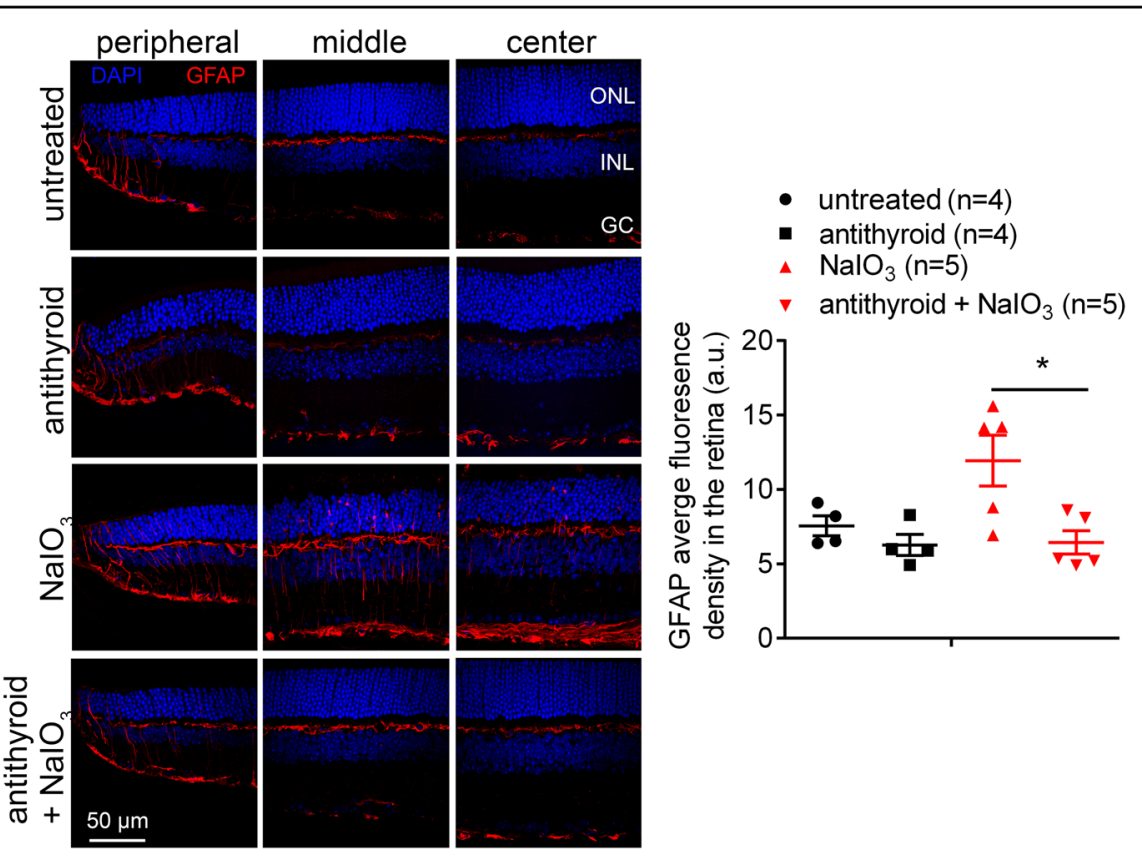

Fig. 5 Treatment with anti-thyroid drug suppressed Müller glia activation induced by $\mathrm{NaIO}_{3}$. GFAP immunofluorescence labeling was performed on the retinal cross sections at 3 days post- $\mathrm{NaIO}_{3}$ injection. Shown are representative confocal images of immunofluorescence labeling of GFAP on the peripheral, middle, and central regions of the retinal sections and corresponding quantification of immunofluorescence intensity. ONL, outer nuclear layer; INL, inner nuclear layer; GC, retinal ganglion cell. Data represented the mean \pm SEM for $4-5$ mice per group $\left({ }^{*} p<0.05\right)$.
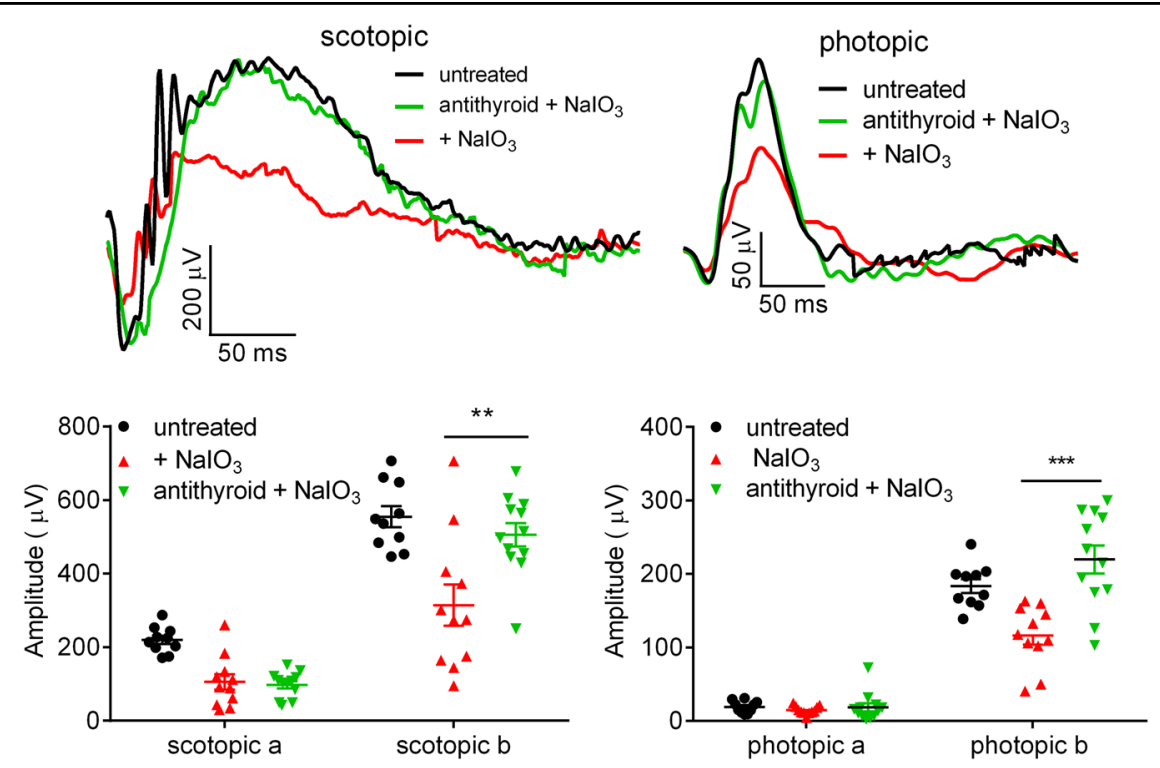

Fig. 6 Treatment with anti-thyroid drug preserved retinal function in mice treated with $\mathrm{NalO}_{3}$. Retinal light responses at 3 days post- $\mathrm{NalO}_{3}$ injection were evaluated by ERG analysis. Shown are representative scotopic and photopic ERG recording waves and quantification of the ERG recordings. Data represented the mean \pm SEM for $10-12$ mice per group $\left({ }^{* *} p<0.01 ;{ }^{* *} p<0.001\right)$.

photoreceptor cell death. However, the anti-thyroid treatment did not rescue the scotopic a-wave, which reflects the responses of rods, though a near complete rescue of retinal morphology and rod number/ONL thickness was achieved (see Fig. 2). The reason behind this observation is unclear at this time. It may suggest a critical regulatory role of $\mathrm{TH}$ signaling in the rod function and needs further investigation.

Although oxidative stress/damage serves as an initiating factor, $\mathrm{NaIO}_{3}$-induced RPE dystrophies/photoreceptor 

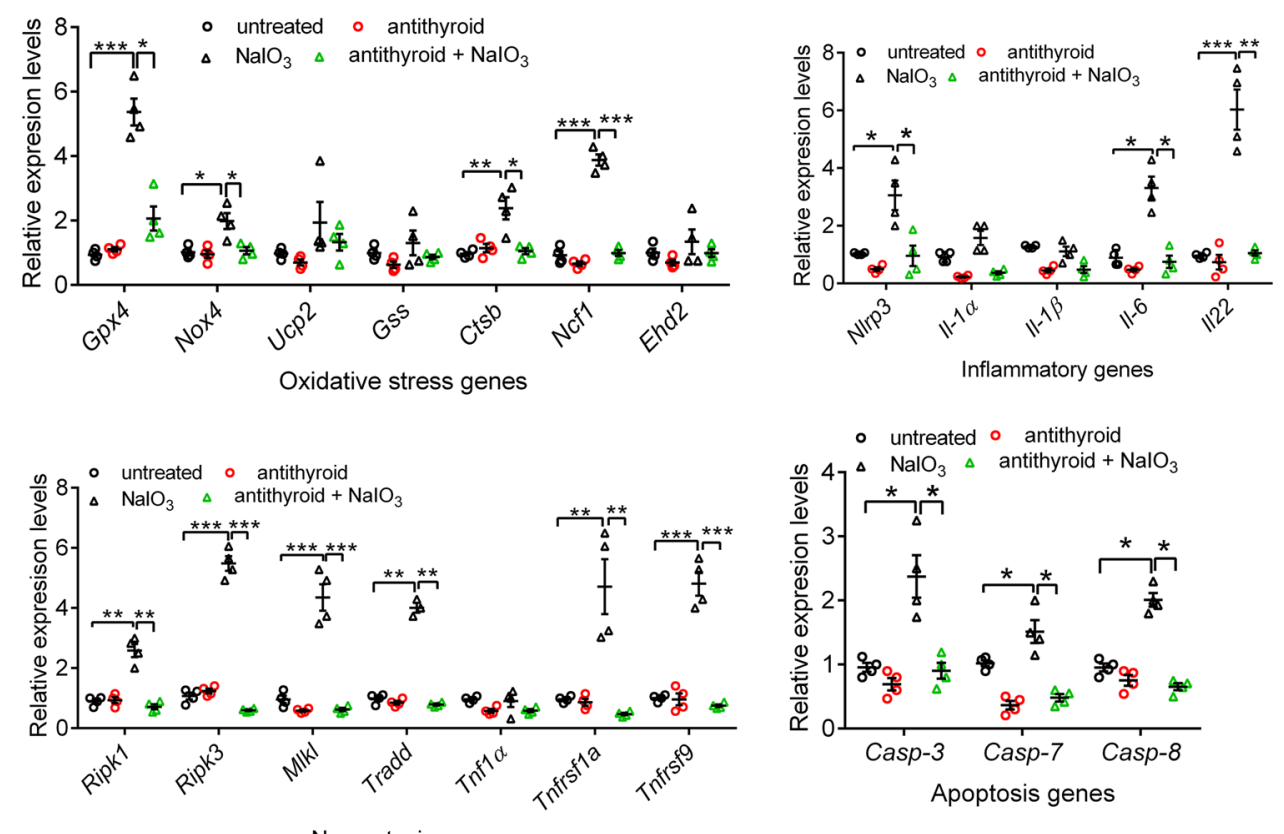

Necroptosis genes

Fig. 7 Treatment with anti-thyroid drug reversed the $\mathrm{NaIO}_{3}$-induced gene expression upregulation in the RPE. Expression levels of the genes involved in cellular stress responses and death signaling were examined in the RPE by qRT-PCR at 1 days post-NalO $\mathrm{O}_{3}$ injection. Shown are expression levels of the genes involved in oxidative stress responses, apoptosis/necroptosis pathways, and inflammatory responses. Data represented the mean \pm SEM for 4 assays using RPE prepared from $5-7$ mice per group $\left({ }^{*} p<0.05,{ }^{* *} p<0.01\right.$, and $\left.{ }^{* *} p<0.001\right)$.
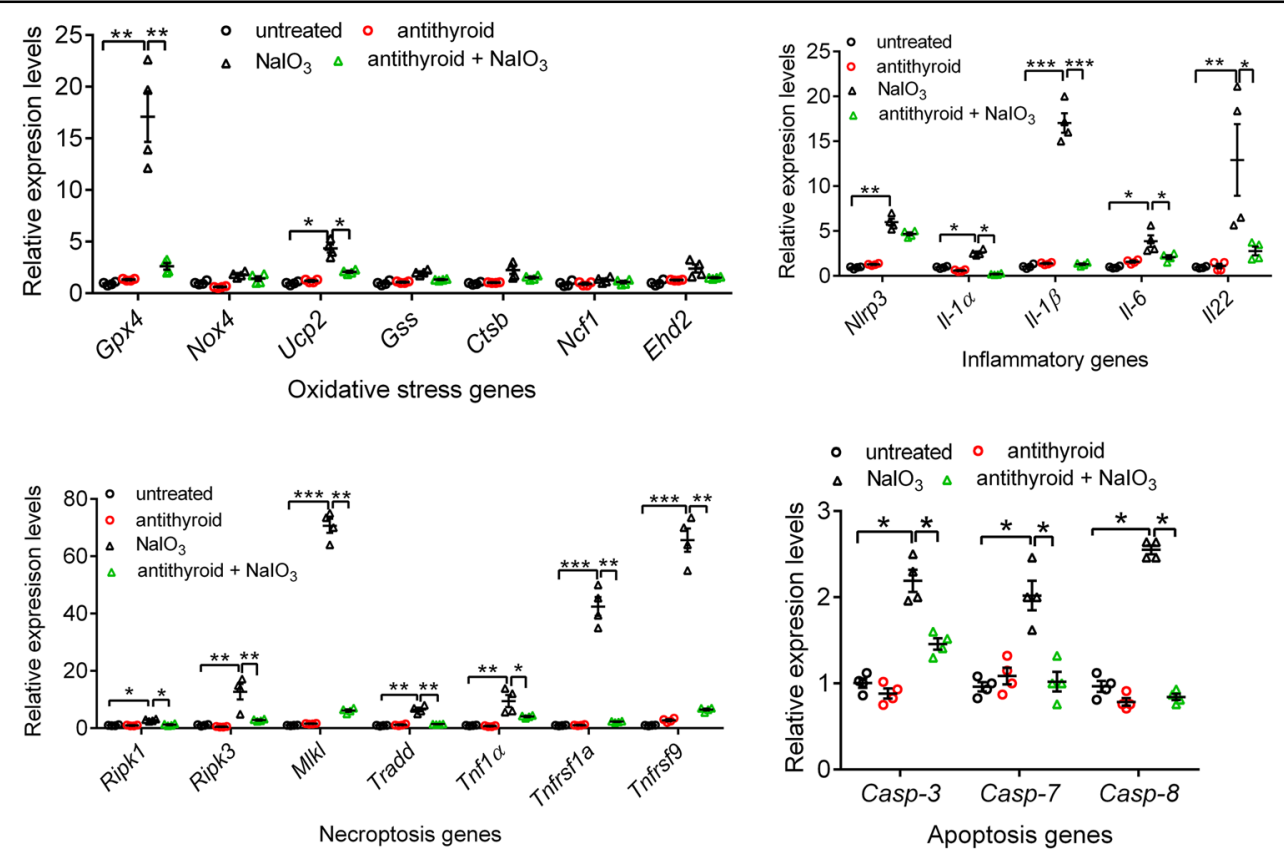

Fig. 8 Treatment with anti-thyroid drug reversed the $\mathrm{NaIO}_{3}$-induced gene expression upregulation in the retina. Expression levels of the genes involved in cellular stress responses and death signaling were examined in the retina by qRT-PCR at 1 days post- $\mathrm{NaIO}_{3}$ injection. Shown are expression levels of the genes involved in oxidative stress responses, apoptosis/necroptosis pathways, and inflammatory responses. Data represented the mean \pm SEM for 4 assays using retinas prepared from 3 mice per group $\left({ }^{*} p<0.05,{ }^{* *} p<0.01\right.$, and $\left.{ }^{* * *} p<0.001\right)$. 
death is a multifactorial condition, triggered by oxidative stress, associated with inflammatory responses, and involves both caspase-dependent and caspase-independent (including necroptosis) mechanisms ${ }^{18-20,30,36,39,40}$. Inhibitors of caspases and necroptotic signaling pathways inhibit RPE and photoreceptor cell death induced by $\mathrm{NaIO}_{3}$ in vivo and in vitro ${ }^{18-20,30,39}$. Consistent with previous reports, this study shows that a single injection of $\mathrm{NaIO}_{3}$ induced upregulation of the genes involved in oxidative stress responses, inflammatory responses, and cellular necroptotic/apoptotic signaling. The local inflammatory responses/innate immune responses were also shown by activation of Müller glia/up-regulation of GFAP. There are a few interesting findings in the gene expression alterations: the apoptotic genes were similarly upregulated in the RPE and retinas; more oxidative stress response genes were upregulated in the RPE, relative to that in the retina; and more significant elevation of the necroptosis genes and inflammatory genes was observed in the retina, relative to that in the RPE. These observations support the view that the oxidative stress responses are the predominant reactions in the RPE whereas the necroptosis/inflammatory responses are the predominant reactions in the retinas. Nevertheless, treatment with anti-thyroid drug effectively suppressed expression of these genes in both RPE and retinas and abolished Müller cell activation. Thus, TH signaling inhibition-induced RPE and photoreceptor protection was likely achieved via multiple mechanisms, including suppression of oxidative stress responses, cell death signaling activity, and inflammatory responses. The question of how inhibition of $\mathrm{TH}$ signaling leads to suppression of these different cellular stress responses/ death activities remains to be addressed. Because $\mathrm{TH}$ signaling plays a pivotal role in mitochondrial metabolism/homeostasis and reactive oxygen species production, one would expect that the anti-oxidative stress effects/protection of mitochondrial homeostasis might be at the core of the $\mathrm{TH}$ signaling inhibition-induced protection. Investigations on the TH regulation of RPE and photoreceptors with a focus on the mitochondrial homeostasis/stress might be particularly significant.

AMD is a multifactorial disorder, involving apoptosis/ necroptosis of both RPE and photoreceptors, triggered by oxidative stress and worsened by inflammatory responses. This work shows that $\mathrm{TH}$ signaling inhibition protected RPE and photoreceptor cells from oxidative damage/cell death in an oxidative stress mouse model of AMD, accompanied by suppression of the upregulation of the genes involved in oxidative stress and inflammatory responses. Results from this animal model study are in line with the clinical findings showing a correlation of high free serum $\mathrm{TH}$ levels with increased risk of AMD, and support a role of $\mathrm{TH}$ signaling in the pathogenesis of AMD. Because both RPE and photoreceptors are involved in the disease pathogenesis and are protected by antithyroid treatment, inhibition of $\mathrm{TH}$ signaling may provide dual benefits in the management of AMD.

In summary, this work investigated the effects of $\mathrm{TH}$ signaling inhibition on $\mathrm{RPE} /$ photoreceptor cell death and retinal function in an $\mathrm{NaIO}_{3}$-induced mouse model of AMD. We show that the anti-thyroid treatment reduced RPE/photoreceptor oxidative damage/cell death, protected retinal function, and suppressed upregulation of the genes involved in cellular oxidative stress responses, cell death pathways, and inflammatory responses. The results of this study demonstrate a role of $\mathrm{TH}$ signaling in the RPE/photoreceptor cell death induced by oxidative stress challenge, and support a role of TH signaling in the pathogenesis of AMD. Further investigation on the regulation of $\mathrm{TH}$ signaling in the RPE and photoreceptor survival will help understand how suppression of TH signaling leads to protection and whether targeting $\mathrm{TH}$ signaling has therapeutic significance for AMD.

\section{Materials and methods \\ Mice and reagents}

C57BL/6J mice were obtained from the Jackson Laboratory and used in this study. Mice were maintained under cyclic light (12-h light-dark) conditions. Cage illumination was 7 -foot-candle during the light cycle. All animal maintenance and experiments were approved by the local Institutional Animal Care and Use Committee (University of Oklahoma Health Sciences Center) and conformed to the guidelines on the care and use of animals adopted by the Society for Neuroscience and the Association for Research in Vision and Ophthalmology. Mice of either sex were used in the experiments. Mice were randomly assigned, within a litter, for the drug treatment or vehicle/untreated experiments; littermate controls were used whenever possible; and no animals were excluded from the analysis. No blinding was carried out for animal experiments.

Alexa Fluor 594 phalloidin (Catalog\#: A12381) and Alexa Fluor 488 donkey anti-rabbit IgG (Catalog\#: A21206) were purchased from Life Technologies; DAPI (4,6-Diamidino-2-phenylindole, Catalog\#: D9542), $\mathrm{NaIO}_{3}$ (Catalog\#: S4007), and PI (Catalog\#: 537059) were purchased from Millipore Sigma; biotinylated PNA (Catalog\#: B-1075) was purchased from Vector Labs; GFAP antibody (Catalog\#: Z0334) was purchased from DAKO; p- $\gamma \mathrm{H} 2 \mathrm{AX}$ antibody (Catalog\#: NB100-2280) was purchased from Novus Biologicals; and 8-OHdG (E8) antibody (Catalog\#: sc393871) was purchased from Santa Cruz Biotechnology, Inc. 


\section{Anti-thyroid treatment and $\mathrm{NaIO}_{3}$ injection}

Anti-thyroid treatment and $\mathrm{NaIO}_{3}$ injection were performed as described previously ${ }^{8,37}$. Briefly, mice received anti-thyroid treatment via drinking water (1\% sodium perchlorate monohydrate and $0.05 \%$ methomazole), beginning at $\mathrm{P} 20$, and received a single injection of $\mathrm{NaIO}_{3}$ $(30 \mathrm{mg} / \mathrm{kg}$, i.p.) at P30. These mice were then analyzed for RPE and photoreceptor damage/cell death and retinal function at 3 days post- $\mathrm{NaIO}_{3}$ injection, and for gene expression alterations at 1 day post- $\mathrm{NaIO}_{3}$ injection.

\section{Measurement of T3 in circulation}

Serum T3 levels were analyzed using a mouse/rat T3 ELISA kit (Catalog\#: T3043T-100, Calbiotech) with a total T3 detection limit at $0.25 \mathrm{ng} / \mathrm{mL}$, as described previously ${ }^{8}$. Briefly, $25 \mu \mathrm{L}$ of serum samples and standards with different T3 concentrations were added into the assigned wells, the assays were performed by following the manufacturer's instruction, and the absorbance of each well was read at $450 \mathrm{~nm}$ (SpectraMax 190 Microplate Spectrophotometer, Molecular Devices). The standard curve was generated by using a three-parameter exponential nonlinear regression in Sigma-Plot software, and the sample T3 concentration was then calculated according to the three-parameter exponential equation.

\section{Eye preparation, immunofluorescence labeling, confocal microscopy, and retinal morphometric analysis}

The RPE whole mounts were prepared for immunofluorescence labeling. Briefly, eyes were enucleated and fixed in $4 \%$ paraformaldehyde (PFA; Polysciences, Inc.) for $1 \mathrm{~h}$ at room temperature, followed by removal of the cornea, lens, muscles, and retina. The RPE sheets (the sclera-choroid-RPE sheets) were then fixed in 4\% PFA for another 1 hour at room temperature, followed by wash (PBS, 5 min 3x) and blocking with 10\% FBS in 0.5\% Triton $\mathrm{X}-100$ in PBS for 1 hour at room temperature. The RPE sheets were then stained with Alexa Fluor ${ }^{\circledR} 594$ phalloidin (1:40) for $30-45 \mathrm{~min}$ at room temperature and DAPI $(1 \mathrm{ng} / \mathrm{mL})$ for another $30 \mathrm{~min}$ at room temperature, followed by wash (PBS, 5 min 2x). The RPE whole mounts were made by transferring the sheets onto the slides, followed by mounting with Hard medium (H-1500, Vector Laboratories).

The retinal whole mounts and cross sections were prepared for immunofluorescence labeling, as described previously $^{8}$. For retinal whole mount preparations, eyes were enucleated, marked at the superior pole with a green dye, and fixed in 4\% PFA for $30 \mathrm{~min}$ at room temperature, followed by removal of the cornea and lens. The eyes were then fixed in 4\% PFA in PBS for 4-6h at room temperature, and retinas were isolated and the superior portion was marked for orientation with a small cut. For retinal cross sections, eyes were enucleated (the superior portion of the cornea was marked with green dye prior to enucleation) and fixed in Prefer (Anatech Ltd.) for 25-30 min at room temperature. Paraffin sections $(5-\mu \mathrm{m}$ thickness) passing vertically through the retina (along the vertical meridian passing through the optic nerve head) were prepared using a Leica microtome (Leica Biosystems). Immunofluorescence labeling was performed as described previously ${ }^{8}$. Briefly, retinal whole mounts or sections were blocked with Hanks' balanced salt solution containing $5 \% \mathrm{BSA}$ and $0.5 \%$ Triton X-100 for $1 \mathrm{~h}$ at room temperature or overnight at $4{ }^{\circ} \mathrm{C}$. Prior to blocking, antigen retrieval was performed in $10 \mathrm{~mm}$ sodium citrate buffer (pH 6.0) for $30 \mathrm{~min}$ in a $70{ }^{\circ} \mathrm{C}$ water bath. Primary antibody incubation (p- $\gamma \mathrm{H} 2 \mathrm{AX}, 1: 200$; GFAP, 1:500; 8-OHdG, 1:200) was performed at room temperature for $2 \mathrm{~h}$, followed by incubation with AlexaFluor- 488 or -568 , or FITC-conjugated secondary antibody. PNA immunohistochemistry was performed using biotinylated PNA (1:250) and streptavidin-Cy3 (1:500).

Low magnification images were taken under the Olympus MVX10 dissection microscope equipped with Image-Pro 6.3 software (Media Cybernetics, Inc.) and high magnification images were taken with an 60X objective on the FV1000 confocal laser scanning microscope equipped with FluoView imaging software (Olympus, Melville). ImageJ software (https://imagej.net/) was used to analyze the damaged area on the RPE whole mounts. For quantification of RPE cell numbers and RPE nuclear numbers, images from four quadrants in the central, middle and peripheral regions were counted and normalized to the number in one square millimeter. Evaluation of cone density on retinal whole mounts was performed as described previously ${ }^{8,41}$. For retinal morphometric analysis, retinal cross sections stained with hematoxylin and eosin (H\&E) were used for morphometric analysis to evaluate ONL integrity/rod survival, as described previously ${ }^{8,42}$.

\section{PI staining and TUNEL assays}

PI staining of RPE whole mounts was performed as described previously ${ }^{18}$. PI $(0.5 \mu \mathrm{g})$ in $50 \mu \mathrm{l}$ PBS was delivered through retro-orbital injection at $15 \mathrm{~min}$ before sacrificing the mice. The enucleated eye globes were fixed in $4 \%$ PFA for 1 hour, anterior part was removed, and the sclera-RPE was fixed in 4\% PFA for one additional hour, followed by DAPI staining and fluorescence microscopy.

Terminal deoxynucleotidyltransferase dUTP nick-end labeling (TUNEL) was performed on paraffin-embedded retinal sections, using an in situ cell death fluorescein detection kit (Sigma-Aldrich, Catalog\#: 11684795910), as described previously ${ }^{43}$. Immunofluorescence labeling was imaged using an Olympus FV1000 confocal laserscanning microscope, and TUNEL-positive cells in the outer nuclear layer passing through the optic nerve were 
counted and averaged from at least 3 sections per eye from 3-5 mice per condition. TUNEL was also performed on RPE whole mounts. Briefly, eyes were fixed in 4\% PFA for 1 hour. The sclera-RPE were then dissected and fixed in 4\% PFA for one additional hour. After antigen retrieval performed in $10 \mathrm{mM}$ sodium citrate buffer ( $\mathrm{pH}$ 6.0) for $30 \mathrm{~min}$ at $70{ }^{\circ} \mathrm{C}$, the sclera-RPE were permeabilized in $1 \%$ Triton X-100 in 10\% FBS for $2 \mathrm{~h}$ at room temperature, followed by labeling using the in situ cell death fluorescein detection kit.

\section{Scotopic and photopic ERG recordings}

Full-field ERG testing was carried out as described previously ${ }^{44}$. Briefly, after overnight dark adaptation, animals were anesthetized by intraperitoneal injection of $85 \mathrm{mg} / \mathrm{kg}$ ketamine and $14 \mathrm{mg} / \mathrm{kg}$ xylazine. ERGs were recorded using an LKC system (Gaithersburg, MD). Potentials were recorded using a platinum wire contacting the corneal surface through a layer of $2.5 \%$ methylcellulose. For assessment of scotopic responses, a stimulus intensity of $1.89 \log \mathrm{cd} \mathrm{s} \mathrm{m}^{-2}$ was presented to darkadapted dilated mouse eyes in a Ganzfeld (GS-2000; Nicolet Instruments, Inc., Madison, WI). To evaluate photopic responses, mice were adapted to a $1.46 \log \mathrm{cd} \mathrm{s}$ $\mathrm{m}^{-2}$ light for $5 \mathrm{~min}$, then a light intensity of $1.89 \log \mathrm{cd} \mathrm{s}$ $\mathrm{m}^{-2}$ was administered. Responses were differentially amplified, averaged, and stored using a Nicolet Compact$4^{\circledR}$ signal averaging system.

\section{RNA isolation and quantitative real-time PCR}

The mouse RPE cells were isolated as described ${ }^{45}$. Total RNA preparation and reverse transcription were performed as described previously ${ }^{46}$. The gene encoding the mouse hypoxanthine guanine phosphoribosyl transferase 1 (Hprt1) was included as an internal control. Supplemental Table 1 shows the primers used. The quantitative real-time PCR (qRT-PCR) assays were performed using a real-time PCR detection system (iCycler; Bio-Rad Laboratories, Hercules, CA, USA), and the relative gene expression value was calculated based on the $\Delta \Delta \mathrm{Ct}$ method, as described previously ${ }^{46}$.

\section{Statistics}

Results are expressed as means \pm SEM of number of mice. Power analysis was performed to choose the sample size. The analysis indicates that a sample size of 3-6 mice/ group for evaluations of retinal degeneration in the mouse retinas will provide at least $80 \%$ power $(1-\beta)$ for a twosided, two-sample $t$-test at a 0.05 alpha level. One-way ANOVA was used to analyze for significance within sets of data, and two-tailed Student's $t$-test was used for differences between two groups of data. Differences were considered statistically significant when $P<0.05$. Statistical tests for every figure are justified as appropriate. Data were analyzed and graphed using GraphPad Prism ${ }^{\circledast}$ software (GraphPad Software, San Diego, CA).

\section{Acknowledgements}

We thank the Imaging Core Facility and the Histology Core Facility of the Department of Cell Biology at the University of Oklahoma Health Sciences Center for technical assistance. This work was supported by the BrightFocus Foundation grant M2018107 and the NIH NEI grant P30EY021725.

Conflict of interest

The authors declare that they have no conflict of interest.

Publisher's note

Springer Nature remains neutral with regard to jurisdictional claims in published maps and institutional affiliations.

Supplementary Information accompanies this paper at (https://doi.org/ 10.1038/s41419-019-2216-7).

Received: 19 June 2019 Revised: 11 December 2019 Accepted: 12 December 2019

Published online: 13 January 2020

\section{References}

1. Friedman, D. S. et al. Prevalence of age-related macular degeneration in the United States. Arch Ophthalmol. 122, 564-572 (2004).

2. Ambati, J. \& Fowler, B. J. Mechanisms of age-related macular degeneration. Neuron 75, 26-39 (2012).

3. Cruz-Guilloty, F. \& Perez, V. L. Molecular medicine: Defence against oxidative damage. Nature 478, 42-43 (2011).

4. Bowes Rickman, C., Farsiu, S., Toth, C. A. \& Klingeborn, M. Dry age-related macular degeneration: mechanisms, therapeutic targets, and imaging. Invest. Ophthalmol. Vis. Sci. 54, 68-80 (2013).

5. Roberts, M. R., Srinivas, M., Forrest, D., Morreale de Escobar, G. \& Reh, T. A. Making the gradient: thyroid hormone regulates cone opsin expression in the developing mouse retina. Proc. Natl Acad. Sci. USA 103, 6218-6223 (2006).

6. $\mathrm{Ng}$, L. et al. A thyroid hormone receptor that is required for the development of green cone photoreceptors. Nat Genet 27, 94-98 (2001).

7. $\mathrm{Ng}$, L. et al. Type 3 deiodinase, a thyroid-hormone-inactivating enzyme, controls survival and maturation of cone photoreceptors. J. Neurosci. 30, 3347-3357 (2010)

8. $\mathrm{Ma}, \mathrm{H}$. et al. Suppressing thyroid hormone signaling preserves cone photoreceptors in mouse models of retinal degeneration. Proc. Natl Acad. Sci. USA 111, 3602-3607 (2014).

9. $\mathrm{Ma}, \mathrm{H}$. et al. Inhibition of thyroid hormone receptor locally in the retina is a therapeutic strategy for retinal degeneration. FASEB J. 31, 3425-3438 (2017).

10. Yang, F. et al. Targeting iodothyronine deiodinases locally in the retina is a therapeutic strategy for retinal degeneration. FASEB J. 30, 4313-4325 (2016).

11. Chaker, L. et al. Thyroid function and age-related macular degeneration: a prospective population-based cohort study-the Rotterdam Study. BMC Med 13, 94 (2015).

12. Gopinath, B., Liew, G., Kifley, A. \& Mitchell, P. Thyroid dysfunction and ten-year incidence of age-related macular degeneration. Invest. Ophthalmol. Vis. Sci. 57, 5273-5277 (2016)

13. Age-Related Eye Disease Study Research, G. Risk factors associated with agerelated macular degeneration. A case-control study in the age-related eye disease study: Age-Related Eye Disease Study Report Number 3. Ophthalmology 107, 2224-2232 (2000).

14. Chatziralli, l., Mitropoulos, P. G., Niakas, D. \& Labiris, G. Thyroidopathy and agerelated macular degeneration: is there any correlation? Biomed. Hub 2, https:// doi.org/10.1159/000454706 (2017).

15. Lin, S. Y. et al. Evidence for an association between macular degeneration and thyroid cancer in the aged population. Int. J. Environ. Res. Public Health 15 https://doi.org/10.3390/ijerph15050902 (2018).

16. Ceresini, G. et al. Thyroid function abnormalities and cognitive impairment in elderly people: results of the Invecchiare in Chianti study. J. Am. Geriatr. Soc. 57, 89-93 (2009). 
17. Kalmijn, S. et al. Subclinical hyperthyroidism and the risk of dementia. The Rotterdam study. Clin. Endocrinol. 53, 733-737 (2000).

18. Hanus, J., Anderson, C., Sarraf, D., Ma, J. \& Wang, S. Retinal pigment epithelial cell necroptosis in response to sodium iodate. Cell Death Discov. 2, 16054 (2016).

19. Hanus, J., Anderson, C. \& Wang, S. RPE necroptosis in response to oxidative stress and in AMD. Ageing Res Rev. https://doi.org/10.1016/j.arr.2015.09.002 (2015).

20. Hanus, J. et al. Induction of necrotic cell death by oxidative stress in retinal pigment epithelial cells. Cell Death Dis. 4, e965 (2013).

21. Kuo, L. J. \& Yang, L. X. Gamma-H2AX - a novel biomarker for DNA doublestrand breaks. In Vivo 22, 305-309 (2008).

22. Kim, G. H. et al. Functional and morphological evaluation of blue lightemitting diode-induced retinal degeneration in mice. Graefes Arch Clin. Exp. Ophthalmol. 254, 705-716 (2016)

23. Reisenhofer, M. H., Balmer, J. \& Enzmann, V. What can pharmacological models of retinal degeneration tell us? Curr. Mol. Med. https://doi.org/10.2174/ 1566524017666170331162048 (2017).

24. Machalinska, A. et al. Sodium iodate selectively injuries the posterior pole of the retina in a dose-dependent manner: morphological and electrophysiological study. Neurochem. Res. 35, 1819-1827 (2010).

25. Kiuchi, K., Yoshizawa, K., Shikata, N., Moriguchi, K. \& Tsubura, A. Morphologic characteristics of retinal degeneration induced by sodium iodate in mice. Curr. Eye Res. 25, 373-379 (2002).

26. Hosoda, L., Adachi-Usami, E., Mizota, A., Hanawa, T. \& Kimura, T. Early effects of sodium iodate injection on ERG in mice. Acta Ophthalmol. 71, 616-622 (1993).

27. Chowers, G. et al. Course of sodium iodate-induced retinal degeneration in albino and pigmented mice. Invest. Ophthalmol. Vis. Sci. 58, 2239-2249 (2017).

28. Zhao, C. et al. mTOR-mediated dedifferentiation of the retinal pigment epithelium initiates photoreceptor degeneration in mice. J. Clin. Invest. 121 369-383 (2011).

29. Korte, G. E., Reppucci, V. \& Henkind, P. RPE destruction causes choriocapillary atrophy. Invest. Ophthalmol. Vis. Sci. 25, 1135-1145 (1984).

30. Jang, K. H. et al. Protective effect of RIPK1-inhibitory compound in in vivo models for retinal degenerative disease. Exp. Eye Res. 180, 8-17 (2019).

31. Cho, B. J., Seo, J. M., Yu, H. G. \& Chung, H. Monocular retinal degeneration induced by intravitreal injection of sodium iodate in rabbit eyes. Jpn. J. Ophthalmol. 60, 226-237 (2016).

32. Nilsson, S. E., Knave, B. \& Persson, H. E. Changes in ultrastructure and function of the sheep pigment epithelium and retina induced by sodium iodate. I. The ultrastructure of the normal pigment epithelium of the sheep. Acta Ophthalmol. 55, 994-1006 (1977).

33. Kiryu, J., Yamamoto, F. \& Honda, Y. Effects of sodium iodate on the electroretinogram c-wave in the cat. Vision Res. 32, 2221-2227 (1992).
34. Mones, J. et al. A swine model of selective geographic atrophy of outer retinal layers mimicking atrophic AMD: a phase I escalating dose of subretinal sodium iodate. Invest. Ophthalmol. Vis. Sci. 57, 3974-3983 (2016).

35. Zhang, X. Y. et al. Continuous exposure to non-lethal doses of sodium iodate induces retinal pigment epithelial cell dysfunction. Sci. Rep. 6, 37279 (2016).

36. Moriguchi, M. et al. Irreversible photoreceptors and RPE cells damage by intravenous sodium iodate in mice is related to macrophage accumulation. Invest. Ophthalmol. Vis. Sci. 59, 3476-3487 (2018).

37. Wang, J., lacovelli, J., Spencer, C. \& Saint-Geniez, M. Direct effect of sodium iodate on neurosensory retina. Invest. Ophthalmol. Vis. Sci. 55, 1941-1953 (2014).

38. Yang, F., Ma, H., Butler, M. R. \& Ding, X. Q. Deficiency of type 2 iodothyronine deiodinase reduces necroptosis activity and oxidative stress responses in retinas of Leber congenital amaurosis model mice. FASEB J. https://doi.org/ 10.1096/fj.201800484RR (2018).

39. Balmer, J., Zulliger, R., Roberti, S. \& Enzmann, V. Retinal cell death caused by sodium iodate involves multiple caspase-dependent and caspaseindependent cell-death pathways. Int. J. Mol. Sci. 16, 15086-15103 (2015).

40. Mao, X. et al. The rescue effect of mesenchymal stem cell on sodium iodateinduced retinal pigment epithelial cell death through deactivation of NFkappaB-mediated NLRP3 inflammasome. Biomed. Pharmacother. 103, 517-523 (2018).

41. $\mathrm{Xu}$, J. et al. cGMP accumulation causes photoreceptor degeneration in CNG channel deficiency: evidence of cGMP cytotoxicity independently of enhanced CNG channel function. J. Neurosci. 33, 14939-14948 (2013).

42. $\mathrm{Xu}$, J. et al. CNGA3 deficiency affects cone synaptic terminal structure and function and leads to secondary rod dysfunction and degeneration. Invest. Ophthalmol. Vis. Sci. 53, 1117-1129 (2012).

43. $\mathrm{Ma}, \mathrm{H}$. et al. cGMP/Protein kinase $\mathrm{G}$ signaling suppresses Inositol 1,4,5-trisphosphate receptor phosphorylation and promotes endoplasmic reticulum stress in photoreceptors of cyclic nucleotide-gated channel-deficient mice. J. Biol. Chem. 290, 20880-20892 (2015).

44. Xu, J., Morris, L., Fliesler, S. J., Sherry, D. M. \& Ding, X. Q. Early-onset, slow progression of cone photoreceptor dysfunction and degeneration in CNG channel subunit CNGB3 deficiency. Invest. Ophthalmol. Vis. Sci. 52, 3557-3566 (2011).

45. Wang, C. X. Z., Zhang, K., Aredo, B., Lu, H. \& Ufret-Vincenty, R. L. Novel method for the rapid isolation of RPE cells specifically for RNA extraction and analysis. Exp. Eye Res. 102C, 1-9 (2012).

46. $\mathrm{Ma}, \mathrm{H}$. et al. Loss of cone cyclic nucleotide-gated channel leads to alterations in light response modulating system and cellular stress response pathways: a gene expression profiling study. Hum. Mol. Genet. 22, 3906-3919 (2013). 